\title{
Association of dysglycemia with mortality in children receiving parenteral nutrition in pediatric intensive care unit
}

\author{
Leila Khajavi ${ }^{1}$, Gholamreza Khademi², Mehraneh Mehramiz¹, Abdolreza Norouzy ${ }^{3}$, \\ Mohammad Safarian ${ }^{3}$ \\ Departments of ${ }^{1}$ Nutrition, ${ }^{2}$ Pediatrics and ${ }^{3}$ Clinical Nutrition, Mashhad University of Medical Sciences, Faculty of \\ Medicine, Mashhad, Iran. \\ E-mail:safarianm@mums.ac.ir \\ Received: 2nd August 2017, Accepted: 17th September 2017
}

\begin{abstract}
SUMMARY: Khajavi L, Khademi G, Mehramiz M, Norouzy A, Safarian M. Association of dysglycemia with mortality in children receiving parenteral nutrition in pediatric intensive care unit. Turk J Pediatr 2018; 60: 134-141.

One of the most important complications of parenteral nutrition (PN) is a high incidence of hyperglycemia. The aim of this study was to assess the effect of parenteral nutrition dysglycemia on clinical outcomes among critically ill children in pediatric intensive care unit (PICU). Charts of 201 critically ill children admitted in PICU during 2012-2015 were reviewed retrospectively. We included patients who were $<6$ years of age and had received at least $60 \%$ of total energy from PN for a minimum of 5 days in PICU. The exclusion criteria were patients with diagnosis of diabetes mellitus, primary hypoglycemia, inborn errors of metabolism and patients who received dialyses. We defined hyperglycemia as blood glucose $\geq 150 \mathrm{mg} / \mathrm{dl}$, and hypoglycemia as blood glucose $\leq 60 \mathrm{mg} / \mathrm{dl}$. Based on blood glucose, patients were divided into four groups: "only hyperglycemia group" (having at least one hyperglycemia episode), "only hypoglycemia group" (having at least one hypoglycemia episode), "glucose variability" (having both hypoglycemia and hyperglycemia episodes), and "normoglycemia" (all glucose measurements were in normal range). Hyperglycemia and hypoglycemia occurred in $52.8 \%$ and $24.9 \%$ of all children, respectively; glucose variability occurred in $13.9 \%$ of all children. Multiple logistic regression analysis showed that glucose variability (OR: 3.1; 95\% CI: 1.13-8.43) and hyperglycemia (OR: 2.14; 95\% CI: 1.1-4.57) were associated with mortality independently. In "only hypoglycemia" group $(\mathrm{N}=22)$ there were only three deaths. There were no significant differences in the quantities of macronutrients prescribed via parenteral nutrition among the four blood glucose groups. Results of this study showed that hyperglycemia and glucose variability are strong predictors of mortality in pediatrics receiving parenteral nutrition.
\end{abstract}

Key words: pediatrics, parenteral nutrition, hyperglycemia, intensive care unit.

Malnutrition in critically ill children is associated with increased length of stay, higher rate of infectious complications and finally higher rate of mortality. ${ }^{1}$ It is well established that parenteral nutrition (PN) has beneficial effects on improving the nutritional status of malnourished children during hospital stay. However, recent studies have shown an increased rate of PN-related complications in critically ill children.2,3

The increased risk of $\mathrm{PN}$-related complications can be associated, among other factors, to the development of hyperglycemia. ${ }^{4}$ Excessive calorie intake, stress, or treatment with steroids may cause hyperglycemia in children receiving PN. ${ }^{5}$ Hyperglycemia is a risk factor for nosocomial infections and increased length of stay in pediatric intensive care unit (PICU), ${ }^{6-8}$ However, there are no clinical trials showing causality. Although hyperglycemia is identified as a risk factor for mortality, there is no effective way to control blood glucose in critically ill children. 
Glucose variability is also common and is harmful for critically ill children.9,10 Although early alterations in blood glucose may be an adaptive response, later changes in blood glucose may be detrimental. ${ }^{11}$ Some studies showed that glucose variability can be more detrimental than sustained hyperglycemia. ${ }^{12}$, 13 Because of PN dextrose infusion, children who receive $\mathrm{PN}$ are less prone to emerge hypoglycemia. Nevertheless, receiving inadequate PN energy and loss of access to the central venous make children who receive PN prone to hypoglycemia. ${ }^{14}$

The usual treatment of hyperglycemia using insulin is not common in pediatric intensive care units because of the higher risk of hypoglycemia with insulin therapy. ${ }^{15,16}$ Some studies showed that hypoglycemia increased mortality in critically ill children. ${ }^{17,} 18$ However, another study could not find this association. ${ }^{10}$

Although there are several studies that examined the association of hyperglycemia with mortality in PICU, these studies did not control the route of receiving nutrition. To the best of our knowledge, the current study is the first study that assess the effects of parenteral nutrition dysglycemia in a heterogeneous sample of critically ill children in PICU. The goal of this study was to investigate the association between

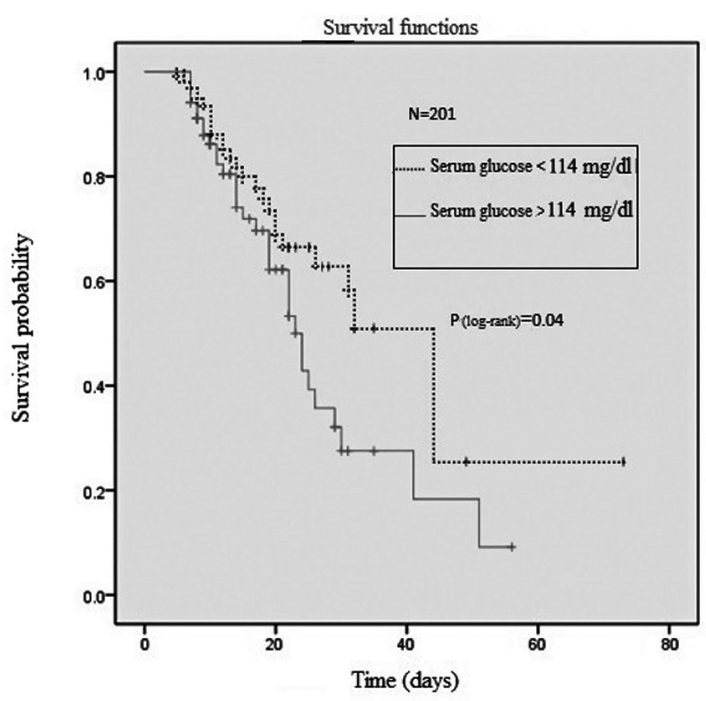

Fig.1. Kaplan-Meier survival curves. OS according to serum glucose in total populations $(n=201)$. $\mathrm{p}$-values were calculated with the log-rank test. dysglycemia (hyperglycemia, hypoglycemia and glucose variability) with mortality in children receiving parenteral nutrition in PICU.

\section{Material and Methods}

The current study was a retrospective cohort chart review analysis of 201 critically ill children admitted to the PICU of Doctor Sheikh Hospital, a pediatric teaching hospital in Mashhad, Iran. The setting for this study was a 22 bed PICU, providing complex medical and surgical care for children. During the study period, there was no standard glucose management protocol and standard nutrition regimen in the setting. The Institutional Review Board at Mashhad University of Medical Sciences approved the study (IR.MUMS.fm.REC.1394.405).

We included patients who were $<6$ years of age and had received at least $60 \%$ of total energy from PN for a minimum of 5 days in PICU. The exclusion criteria were patients with diagnosis of diabetes mellitus, primary hypoglycemia, inborn errors of metabolic and patients who received dialyses. For patients with multiple hospital admissions, only the first admission was included. List of patients who were admitted to PICU between the years 2012 to 2015 was obtained from an electronic database in hospital administrative. Patients' unique medical numbers were extracted from electronic database to find their charts in hospital archive. Data were collected manually by a researcher from charts. Information extracted from the charts included: patients' demographics, medical vs. surgical therapy, length of stay in hospital and PICU, days on ventilator, days on $\mathrm{PN}$, comorbidities, all laboratory data and all the serums and enteral nutrition. The Pediatric Risk of Mortality (PRISM) III score was calculated for every patient based on the first 24 hours of PICU admission for illness severity.

Capillary blood glucose levels were measured using a glucometer and test strip (Easy GlucoKorea). All capillary blood glucoses were collected from charts. We defined hyperglycemia as blood glucose level $\geq 150 \mathrm{mg} / \mathrm{dl}$, and hypoglycemia as glucose level $\leq 60 \mathrm{mg} / \mathrm{dl}$; based on previous studies. ${ }^{10,17}$. Based on blood glucose, patients were divided into four groups: "only hyperglycemia group" (having at least one hyperglycemia episode and other measurements normal), "only hypoglycemia 
Table I. General Characteristics of the Study Group

\begin{tabular}{lc}
\hline Characteristics & Results \\
\hline Age group, N (\%) & $126(62.7)$ \\
$\quad$ Neonate & $64(31.8)$ \\
$\quad$ Infant & $11(5.5)$ \\
Child & $105(52.2)$ \\
Male, N (\%) & $133(66.2)$ \\
Diagnosis, N (\%) & $68(33.8)$ \\
$\quad$ Surgery & $8.3 \pm 5.7$ \\
$\quad$ Non-surgery & $16.1 \pm 10.2$ \\
PRISM III score & $5.0 \pm 8.2$ \\
PICU length of stay (days) & $12.7 \pm 8.5$ \\
Duration of mechanical ventilation (days) & $9.6 \pm 10.5$ \\
Duration on parenteral nutrition (days) & $3.3 \pm 2.2$ \\
Number of blood glucose measurements & $114.1 \pm 27.4$ \\
Weight (kg) & $3.17 \pm 0.5$ \\
Capillary blood glucose (mg/dl) & $28.0 \pm 24.6$ \\
Albumin (g/dl) & $94(46.8)$ \\
hs-CRP (mg/dl) & \\
Infectious complication, N (\%) & \\
\hline
\end{tabular}

hs-CRP: high-sensitive C-reactive protein; PRISM III: Pediatric Risk of Mortality-III Score

group" (having at least one hypoglycemia episode and other measurements normal), "glucose variability" (having both hypoglycemia and hyperglycemia episodes in a single PICU admission), "normoglycemia" (any patient that all his/her measurements were normal).

\section{Statistical analysis}

We used SPSS12 for statistical analysis. The data are presented as the mean $\pm \mathrm{SD}$. To compare continuous variables between survivors and non-survivors, Student's t test or MannWhitney U test was used. Differences in four blood glucose groups were compared using ANOVA test or Kruskal-Wallis test. Chi square test was used for comparison of data between two qualitative variables. Multivariate analysis was conducted with logistic regression models. Overall survival (OS) was evaluated from the day of starting PN to the end point, i.e. death or discharge following Kaplan-Meier method, and compared by log-rank test. All the calculations were two-sided and with statistical significance at $\mathrm{p}<0.05$.

\section{Results}

Two-hundred-eighty-two children who received parenteral nutrition were identified between 2012-2015; 201 patients including 126 neonates, 64 infants and 11 children met inclusion criteria. Mean blood glucose for these 201 patients was $114.1 \pm 27.4 \mathrm{mg} / \mathrm{dl}$. Of the study patients, $66.2 \%$ were surgical patients and $33.8 \%$ were medical patients. Only $1.9 \%$ of $(\mathrm{N}=4)$ patients received insulin during PN infusion. Table I demonstrates patients' characteristics.

There were 66 deaths $(33.3 \%)$ in PICU. Table II shows the characteristics of survivors and non-survivors. Non-survivors had higher mean blood glucose concentration than survivors. Days on TPN were longer among non-survivors, compared to survivors; however, days on PPN were longer among survivors, compared to nonsurvivors. There were significant differences between group for days on mechanical ventilation, albumin level, PRISM III score, development of infectious complications and presence of comorbidity between survivors and non-survivors.

Table III shows the characteristics of patients for each blood glucose group; $52.8 \%$ of the patients experienced hyperglycemia (only hyperglycemia and glucose variability). Hypoglycemia (only hypoglycemia and glucose variability) occurred in $24.9 \%$ of the patients. A normal blood glucose range was maintained for $37.3 \%$ of 
Table II. Characteristics of Survivors and Non-Survivors.

\begin{tabular}{|c|c|c|c|}
\hline Characteristics & Survivors (N: 135) & Non survivors (N: 66) & p-value \\
\hline Age (months) & $2.7 \pm 8.4$ & $4.1 \pm 10.0$ & 0.82 \\
\hline PICU length of stay (days) & $17.1 \pm 10.4$ & $15.7 \pm 10.1$ & 0.26 \\
\hline Duration of MV (days) & $3.5 \pm 7.2$ & $8.2 \pm 9.4$ & $<0.001$ \\
\hline Duration of TPN (days) & $8.1 \pm 6.0$ & $11.7 \pm 8.6$ & 0.004 \\
\hline Duration of PPN (days) & $4.2 \pm 4.7$ & $1.6 \pm 2.7$ & $<0.001$ \\
\hline $\begin{array}{l}\text { Weight for age, } \mathrm{N}(\%) \\
\text { Z-score } \leq-2 ;>-3 \\
\text { Z-score }<-3 \\
\text { Mean capillary blood glucose }(\mathrm{mg} / \mathrm{dl})\end{array}$ & $\begin{array}{ll}23 & (19.3) \\
41 & (30.3) \\
110.6 \pm 4.3\end{array}$ & $\begin{array}{ll}21 & (31.8) \\
30 & (45.4) \\
120.8 \pm 2.5\end{array}$ & 0.002 \\
\hline Albumin (g/dl) & $3.1 \pm 0.5$ & $2.8 \pm 0.4$ & $<0.001$ \\
\hline hs-CRP (mg/dl) & $25.8 \pm 21.4$ & $32.1 \pm 30.2$ & 0.9 \\
\hline $\begin{array}{l}\text { Diagnosis, N (\%) } \\
\text { Surgery } \\
\text { Non-surgery } \\
\text { PRISM-III score }\end{array}$ & $\begin{array}{l}94(69.7) \\
41(30.3) \\
7.6 \pm 5.6\end{array}$ & $\begin{array}{l}39(59.1) \\
27(40.9) \\
9.7 \pm 5.8\end{array}$ & 0.016 \\
\hline Infectious complication, $\mathrm{N}(\%)$ & $52(38.5)$ & $42(63.6)$ & $<0.001$ \\
\hline Steroids, N (\%) & $47(34.8)$ & $24(36.4)$ & 0.07 \\
\hline Comorbidity, N (\%) & $19(14.1)$ & $24(36.4)$ & 0.05 \\
\hline
\end{tabular}

hs-CRP: high-sensitivity C-reactive protein; MV: mechanical ventilation; PPN: partial parenteral nutrition; PRISM-III: Pediatric Risk of Mortality-III Score; TPN: total parenteral nutrition

patients throughout receiving PN nutrition. Glucose variability (both hypoglycemia and hyperglycemia) occurred in $13.9 \%$ of patients. PICU LOS, days on ventilator, days on TPN, infectious complications and death were significantly higher among hyperglycemia and glucose variability groups. PRISM III score was significantly higher among glucose variability group.

The macronutrients composition of the PN prescriptions is shown in Table IV. As data revealed there were no significant differences in the quantities of macronutrients among the four blood glucose groups in neonates and non-neonates.

Table $\mathrm{V}$ shows the multiple logistic regression analysis for the risk of PICU death. Hyperglycemia group and glucose variability group had a risk of mortality that was 2.1 and 3.0 times greater than normoglycemia group, respectively, after adjusting for PRISMIII score, comorbidity and $(\mathrm{OR}=2.14 ; 95 \% \mathrm{CI}$ 1.0 - 4.57), days on ventilator $(\mathrm{OR}=3.08 ; 95 \%$ CI 1.13-8.43).

As shown in the Kaplan-Meier curve in Figure 1, hyperglycemia was associated with significantly differential OS. The patients with serum glucose more than median had a median OS of 23 days (95\% CI 19-26), whereas patients with the serum glucose less than median had a median OS of 44 days (95\% CI 4.33-54; log-rank $\mathrm{p}=0.04$ ).

\section{Discussion}

The aim of our study was to assess the association of parenteral nutrition dysglycemia with mortality and other clinical outcomes in critically ill children in PICU.

Prevalence of hyperglycemia was high in our study and the results showed that hyperglycemia and glucose variability were independently associated with mortality in critically ill children receiving parenteral nutrition. Hyperglycemia and glucose variability also were associated with increased length of stay in PICU, increased days on ventilator and increased infection. Highest rate of mortality was found in glucose variability group. In our study, hypoglycemia was not associated with increased mortality and morbidity. There were no significant differences in the quantities of macronutrients prescribed among the four blood glucose groups.

Growing bodies of evidence studied the association of hyperglycemia with mortality 
Table III. Differences Between Blood Glucose Groups.

\begin{tabular}{|c|c|c|c|c|c|}
\hline \multirow[b]{2}{*}{ Characteristics } & \multicolumn{5}{|c|}{ Blood glucose groups } \\
\hline & $\begin{array}{l}\text { Normoglycemia } \\
(\mathrm{N}: 75)\end{array}$ & $\begin{array}{l}\text { Only } \\
\text { hypoglycemia } \\
\text { (N: 22) }\end{array}$ & $\begin{array}{l}\text { Only } \\
\text { hyperglycemia } \\
(\mathrm{N}: 76)\end{array}$ & $\begin{array}{l}\text { Glucose } \\
\text { variability } \\
(\mathrm{N}: 28)\end{array}$ & $P$ value \\
\hline Age (month) & $2.0 \pm 5.6$ & $1.76 \pm 3.0$ & $4.93 \pm 12.7$ & $2.6 \pm 6.4$ & 0.25 \\
\hline $\begin{array}{l}\text { PICU length of stay } \\
\text { (days) }\end{array}$ & $13.9 \pm 8.5$ & $17.3 \pm 14.5$ & $16.9 \pm 10.5$ & $19.2 \pm 9.3$ & 0.029 \\
\hline Duration of MV (days) & $3.4 \pm 5.6$ & $4.1 \pm 12$ & $5.6 \pm 8.7$ & $8.6 \pm 8.4$ & $<0.001$ \\
\hline Duration of TPN (days) & $7.9 \pm 5.9$ & $9.1 \pm 7.1$ & $9.3 \pm 7.1$ & $13.3 \pm 8.7$ & 0.017 \\
\hline Duration of PPN (days) & $3.2 \pm 3.4$ & $2.8 \pm 7.4$ & $3.2 \pm 3.8$ & $5.0 \pm 4.6$ & 0.286 \\
\hline Death, N (\%) & $16(21.3)$ & $3(13.6)$ & $31(40.8)$ & $16(57.1)$ & $<0.001$ \\
\hline $\begin{array}{l}\text { Weight for age, } \mathrm{N}(\%) \\
\text { Z-score } \leq-2 ;>-3 \\
\text { Z-score }<-3\end{array}$ & $\begin{array}{ll}19 & (25.3) \\
16 & (21.4)\end{array}$ & $\begin{array}{l}1(4.5) \\
15(68.1)\end{array}$ & $\begin{array}{l}18(23.6) \\
25(32.8)\end{array}$ & $\begin{array}{l}7(25) \\
15(53.5)\end{array}$ & 0.03 \\
\hline $\begin{array}{l}\text { Mean capillary blood } \\
\text { glucose (mg/dl) }\end{array}$ & $102.5 \pm 13.2$ & $79.3 \pm 14.6$ & $130.7 \pm 25$ & $118.8 \pm 28.1$ & $<0.001$ \\
\hline $\operatorname{Albumin}(\mathrm{g} / \mathrm{dl})$ & $3.2 \pm 0.5$ & $2.8 \pm 0.4$ & $3.2 \pm 0.5$ & $3 \pm 0.4$ & 0.4 \\
\hline hs-CRP (mg/dl) & $29.5 \pm 22.8$ & $28.1 \pm 28$ & $20.2 \pm 18.1$ & $39.2 \pm 31$ & 0.2 \\
\hline $\begin{array}{l}\text { Diagnosis, N (\%) } \\
\text { Surgery } \\
\text { Non-surgery }\end{array}$ & $\begin{array}{ll}48 & (64) \\
27 & (36)\end{array}$ & $\begin{array}{l}15(68.2) \\
7(31.8)\end{array}$ & $\begin{array}{ll}53 & (69.7) \\
23 & (30.3)\end{array}$ & $\begin{array}{ll}17(60.7) \\
11(39.3)\end{array}$ & 0.8 \\
\hline PRISM-III score & $7.1 \pm 4.9$ & $8.2 \pm 6.3$ & $8.5 \pm 5.6$ & $11.2 \pm 6.5$ & 0.03 \\
\hline $\begin{array}{l}\text { Infectious complication, } \\
\text { N (\%) }\end{array}$ & $25(33.3)$ & $8(36.4)$ & $43(56.6)$ & $18(64.3)$ & 0.006 \\
\hline Steroids, N (\%) & $22(29.3)$ & $6(27.3)$ & $31(40.8)$ & $12(42.8)$ & 0.32 \\
\hline Comorbidity, N (\%) & $14(18.6)$ & $1(4.5)$ & $20(26.3)$ & $8(28.6)$ & 0.11 \\
\hline
\end{tabular}

hs-CRP: high-sensitivity C-reactive protein; LOS: length of stay; PPN: partial parenteral nutrition; PRISM III: Pediatric Risk of Mortality-III Score; TPN: total parenteral nutrition

in PICU without considering the route of nutrition. The current study is the first study that evaluated the effects of parenteral nutrition dysglycemia in a heterogeneous sample of critically ill children in PICU.

Hyperglycemia was related to increased infection in different groups of critically ill children. ${ }^{6,7,19}$ In our study there was a significant association between hyperglycemia and increased infection. Increased incidence of infection by hyperglycemia is because of direct relation of hyperglycemia with immune dysfunction. ${ }^{20}$ Hyperglycemia impairs complement fixation and changes macrophage and neutrophil activity (via reduced phagocytosis). 21,22

In our study, like previous studies, hyperglycemia was associated with increased days on ventilator. Hyperglycemia increases days on ventilator directly via harming lungs and indirectly by development of critical illness myopathy. ${ }^{23}$
There are two main reasons for developing hyperglycemia during critical illness. First, metabolic changes during critical illness which were characterized with increased gluconeogenesis and development of insulin resistance. ${ }^{24}$ Second reason is overfeeding specifically via parenteral nutrition. ${ }^{19}$

In the present study, average calorie intake was $53.4 \mathrm{Kcal} / \mathrm{kg}$ per day and there was no significant difference in calorie and macronutrients intake among the four blood glucose groups. It seems, in the present study, hyperglycemia was not due to overfeeding. In other study, Alaedeen et al. ${ }^{19}$ found that calorie intake in the first week of parenteral nutrition was $83 \mathrm{Kcal} / \mathrm{kg}$ per day in premature newborns. It should be considered that maximum intake of energy should not be more than $60 \mathrm{Kcal} /$ $\mathrm{kg}$ in a day in acute phase of critical illness. ${ }^{25}$ Therefore, they concluded that overfeeding 
Table IV. Energy and Macronutrient Composition of Parenteral Nutrition According to Blood Glucose Groups.

\begin{tabular}{llllll}
\hline \multirow{2}{*}{ Content } & \multicolumn{4}{c}{ Blood glucose groups } & P value \\
\cline { 2 - 4 } & Normoglycemia & $\begin{array}{l}\text { Only } \\
\text { hypoglycemia }\end{array}$ & $\begin{array}{l}\text { Only } \\
\text { hyperglycemia }\end{array}$ & $\begin{array}{l}\text { Glucose } \\
\text { variability }\end{array}$ & \\
\hline $\begin{array}{l}\text { Calories (Kcal/kg/day) } \\
\quad \text { Neonates }\end{array}$ & $54.9 \pm 14.6$ & $59.0 \pm 12.4$ & $58.4 \pm 17.8$ & $59.0 \pm 17.0$ & 0.60 \\
$\quad \begin{array}{l}\text { Non-neonates } \\
\text { Carbohydrate (g/kg/day) }\end{array}$ & $42.6 \pm 13.8$ & $44.5 \pm 17.0$ & $50.7 \pm 15.5$ & $44.8 \pm 15.6$ & 0.20 \\
$\quad$ Neonates & $9.2 \pm 2.3$ & $9.0 \pm 2.3$ & $9.5 \pm 3.7$ & $9.7 \pm 2.8$ & 0.80 \\
$\quad$ Non-neonates & $6.6 \pm 2.1$ & $7.1 \pm 2.4$ & $8.0 \pm 2.4$ & $7.2 \pm 2.7$ & 0.20 \\
Amino acids (g/kg/day) & & & & & \\
$\quad$ Neonates & $1.4 \pm 0.7$ & $1.8 \pm 0.5$ & $1.9 \pm 1.1$ & $1.7 \pm 0.8$ & 0.07 \\
$\quad$ Non-neonates & $1.3 \pm 0.6$ & $1.5 \pm 0.8$ & $1.7 \pm 0.9$ & $1.4 \pm 0.6$ & 0.40 \\
Fat (g/kg/day) & & & & & \\
$\quad$ Neonates & $1.3 \pm 0.7$ & $1.7 \pm 0.5$ & $1.3 \pm 0.7$ & $1.4 \pm 0.8$ & 0.30 \\
$\quad$ Non-neonates & $1 \pm 0.7$ & $1.1 \pm 0.8$ & $1.3 \pm 0.8$ & $1.2 \pm 0.7$ & 0.50 \\
\hline
\end{tabular}

Table V. Factors Associated with Mortality.

\begin{tabular}{lllll}
\hline Factors & $\mathrm{B}$ & Odds ratio & $95 \%$ CI & p value \\
\hline Comorbidity & 0.98 & 2.60 & $1.26-5.7$ & 0.010 \\
Days on mechanical ventilation & 0.05 & 1.05 & $1.01-1.1$ & 0.009 \\
PRISM-III score & 0.05 & 1.06 & $0.99-1.12$ & 0.050 \\
Blood glucose group* & & & & 0.02 \\
$\quad$ Only hyperglycemia & 0.76 & 2.14 & $1.0-4.57$ & 0.04 \\
$\quad$ Glucose variability & 1.12 & 3.08 & $1.13-8.43$ & 0.02 \\
$\quad$ Only hypoglycemia & -0.61 & 0.54 & $0.12-2.31$ & 0.40 \\
\hline
\end{tabular}

CI: confidence interval

*reference: normoglycemia

might happen and cause hyperglycemia in their studied population.

Risk of development of hypoglycemia in children receiving parenteral nutrition is low because of dextrose infusion. Age is a risk factor for hypoglycemia. In our study, younger children were at higher risk of hypoglycemia; however, it was not statistically significant. Ognibene et al. ${ }^{17}$ also demonstrated that younger children were at higher risk of hypoglycemia. It seems that age dependent differences in $\beta$-cell function is the cause of hypoglycemia in neonates. ${ }^{26}$

Growth-restricted children also are at higher risk of hypoglycemia. ${ }^{27}$ In our study, severe underweight was more prevalent among hypoglycemia group.

Whether hypoglycemia leads to death in critically ill children is controversial. In our study hypoglycemia was not associated with mortality and length of stay in PICU. These findings are consistent with results of Hirshberg et al. ${ }^{10}$ who did not find any association between hypoglycemia $(\leq 60 \mathrm{mg} / \mathrm{dl})$ and mortality.

Logistic regression analysis showed that glucose variability had strongest association with mortality in comparison with other blood glucose groups. These results confirm previous studies that glucose variability increased mortality. ${ }^{10,18}$ The highest mean of PRISM-III score was in glucose variability group, and the lowest score was in normal blood glucose group and this difference was statistically significant.

Some non-ICU studies support this hypothesis that glucose variability may be more harmful than sustained hyperglycemia. ${ }^{12,13}$ Risso et al. ${ }^{12}$ exposed umbilical vein cells to sustained hyperglycemia or glucose variability condition and found that apoptosis was significantly higher in glucose variability condition. 
Our study had some limitations. First, it was a single-center retrospective study that may attenuate the importance of clinical findings of the study. Second, there was not a standard protocol for parenteral nutrition and glucose control in the setting. Third, if the sample size was larger we could better distinguish the effect of hypoglycemia on mortality.

In conclusion; hyperglycemia and glucose variability was prevalent in children receiving parenteral nutrition. Hyperglycemia and glucose variability were independently associated with mortality after adjusting for illness severity (PRISM-III), comorbidity and days on ventilator. Glucose variability had stronger association with mortality in comparison with hyperglycemia. In our study, prevalence of hypoglycemia was lower than hyperglycemia and glucose variability. Hypoglycemia was not associated with mortality and poor clinical outcomes. The best range for controlling blood glucose in children receiving parenteral nutrition needs prospective multicenter studies with larger sample size.

\section{REFERENCES}

1. Kyle UG, Jaimon N, Coss-Bu JA. Nutrition support in critically ill children: Underdelivery of energy and protein compared with current recommendations. J Acad Nutr Diet 2012; 112: 1987-1992.

2. Fivez T, Kerklaan D, Mesotten D, et al. Early versus late parenteral nutrition in critically ill children. $\mathrm{N}$ Engl J Med 2016; 374: 1111-1122.

3. Peyret B, Collardeau S, Touzet S, et al. Prevalence of liver complications in children receiving long-term parenteral nutrition. Eur J Clin Nutr 2011; 65: 743749 .

4. Rosmarin DK, Wardlaw GM, Mirtallo J. Hyperglycemia associated with high, continuous infusion rates of total parenteral nutrition dextrose. Nutr Clin Pract 1996; 11: 151-156.

5. Mitanchez D. Glucose regulation in preterm newborn infants. Horm Res Paediatr 2007; 68: 265-271.

6. Lou S, MacLaren G, Paul E, Best D, Delzoppo C, Butt W. Prevalence of dysglycemia and association with outcomes in pediatric extracorporeal membrane oxygenation. Pediatr Crit Care Med 2015; 16: 270-275.

7. Wu Y, Pei J, Yang X-d, Zhao Y-y, Xiang B. Hyperglycemia and its association with clinical outcomes for patients in the pediatric intensive care unit after abdominal surgery. J Pediatr Surg 2013; 48: 801-805.

8. Yung M, Wilkins B, Norton L, Slater A, Group PS. Glucose control, organ failure, and mortality in pediatric intensive care. Pediatr Crit Care Med 2008; 9: 147-152.
9. Rake AJ, Srinivasan V, Nadkarni V, Kaptan R, Newth CJ. Glucose variability and survival in critically ill children: allostasis or harm? Pediatr Crit Care Med 2010; 11: 707-712.

10. Hirshberg E, Larsen G, Van Duker H. Alterations in glucose homeostasis in the pediatric intensive care unit: Hyperglycemia and glucose variability are associated with increased mortality and morbidity. Pediatr Crit Care Med 2008; 9: 361-366.

11. Srinivasan V. Stress hyperglycemia in pediatric critical illness: the intensive care unit adds to the stress! J Diabetes Sci Technol 2012; 6: 37-47.

12. Risso A, Mercuri F, Quagliaro L, Damante G, Ceriello A. Intermittent high glucose enhances apoptosis in human umbilical vein endothelial cells in culture. Am J Physiol Endocrinol Metab 2001; 281: 924-930.

13. Quagliaro L, Piconi L, Assaloni R, Martinelli L, Motz E, Ceriello A. Intermittent high glucose enhances apoptosis related to oxidative stress in human umbilical vein endothelial cells. Diabetes 2003; 52: 2795-2804.

14. Sperling MA, Menon RK. Differential diagnosis and management of neonatal hypoglycemia. Pediatr Clin North Am 2004; 51: 703-723.

15. Macrae D, Grieve R, Allen E, et al. A randomized trial of hyperglycemic control in pediatric intensive care. N Engl J Med 2014; 370: 107-118.

16. Srinivasan V, Agus MS. Tight glucose control in critically ill children-a systematic review and meta-analysis. Pediatr Diabetes 2014; 15: 75-83.

17. Ognibene KL, Vawdrey DK, Biagas KV. The association of age, illness severity, and glycemic status in a pediatric intensive care unit. Pediatr Crit Care Med 2011; 12: 386-390.

18. Wintergerst KA, Buckingham B, Gandrud L, Wong BJ, Kache S, Wilson DM. Association of hypoglycemia, hyperglycemia, and glucose variability with morbidity and death in the pediatric intensive care unit. Pediatrics 2006; 118: 173-179.

19. Alaedeen DI, Walsh MC, Chwals WJ. Total parenteral nutrition-associated hyperglycemia correlates with prolonged mechanical ventilation and hospital stay in septic infants. J Pediatr Surg 2006; 41: 239-244.

20. Van den Berghe G. How does blood glucose control with insulin save lives in intensive care? J Clin Invest 2004; 114: 1187-1195.

21. Goldberg PA, Inzucchi SE. Critical issues in endocrinology. Clin Chest Med 2003; 24: 583-606.

22. McMahon MM, Bistrian BR. Host defenses and susceptibility to infection in patients with diabetes mellitus. Infect Dis Clin North Am 1995; 9: 1-9.

23. Stevens RD, Dowdy DW, Michaels RK, Mendez-Tellez PA, Pronovost PJ, Needham DM. Neuromuscular dysfunction acquired in critical illness: A systematic review. Intensive Care Med 2007; 33: 1876-1891.

24. Mechanick JI. Metabolic mechanisms of stress hyperglycemia. J Parenter Enteral Nutr 2006; 30: 157-163. 
25. Chwals WJ, Letton RW, Jamie A, Charles B. Stratification of injury severity using energy expenditure response in surgical infants. J Pediatr Surg 1995; 30: 1161-1164.

26. Preissig CM, Rigby MR. Pediatric critical illness hyperglycemia: risk factors associated with development and severity of hyperglycemia in critically ill children. J Pediatr 2009; 155: 734-739.
27. Arsenault D, Brenn M, Kim S, Gura K, Compher C, Simpser E; American Society for Parenteral and Enteral Nutrition Board of Directors, Puder M. A.S.P.E.N. Clinical Guidelines: Hyperglycemia and hypoglycemia in the neonate receiving parenteral nutrition. JPEN J Parenter Enteral Nutr 2012; 36: 81-95. 